УДК 330

DOI: $10.36461 /$ NP.2019.52.3.008

\title{
К ПРОБЛЕМЕ ВОСПРОИЗВОДСТВА ЗЕМЕЛЬНЫХ РЕСУРСОВ ПЕНЗЕНСКОЙ ОБЛАСТИ
}

Е. Н. Никифорова, канд. экон. наук, профессор; Ю. Ю. Рассыпнова, доцент; Н. М. Гурьянова, канд. экон. наук, доцент

Федеральное государственное бюджетное образовательное учреждение высшего образования «Пензенский государственный аграрный университет», Россия, т. (841-2) 628-376, e-mail: rzyankina-natalya@yandex.ru

В статье представлен материал по проблеме воспроизводства земельных ресурсов Пензенской области, основные аспекты которых сегодня являются ключевыми и входят в качестве приоритетных направлений реализации ряда государственных программ и иных законодательных актов. Авторами затрагивается проблема распределения земель сельскохозяйственного назначения по различным формам собственности и по угодьям. Система воспроизводства земельных ресурсов строится на интеграции правового, организационного, учетного, функционального аспектов и контроле за целевым их использованием. Эффективность данной системы выражается в результативных показателях: урожайность сельскохозяйственных культур, валовой сбор, бонитет почвы. В качестве сравнительных характеристик процесса воспроизводства могут использоваться и относительные переменные: объем производства продукции в расчете на один балл бонитета почвы или на рубль кадастровой стоимости земли.

Ключевые слова: воспроизводство, земли сельскохозяйственного назначения, распределение земель, сельскохозяйственное производство.

\section{Введение}

Пензенская область небогата минеральными ресурсами: недра содержат фосфоритовые руды, глауконитосодержащие породы, торф, строительные материалы, нефть низкого качества. Главным природным богатством является земля.

В 2018 году в консолидированный бюджет Пензенской области поступило 61,2 миллиона рублей платежей за пользование природными ресурсами и 1006,2 миллиона рублей земельного налога.

Воспроизводство земельных ресурсов и повышение эфффективности их использования в сельском хозяйстве рассматриваются сегодня как одно из первостепенных направлений реализации государственной программы Пензенской области «Развитие агропромышленного комплекса Пензенской области на 2014-2022 годы».

Под воспроизводством земельных ресурсов принято понимать непрерывное возобновление потребительских свойств, производительных качеств земли как фрактора производства продукции и возобновление земельных отношений, которые охватывают процессы производства, распределения, обмена, потребления и являются объектом постоянного экономического интереса.

Неполное суженное воспроизводство плодородия свойственно техногенному типу развития аграрного производства, про- стое и расширенное воспроизводство соответствуют природоохранному и природоулучшающему типам производства и способствуют устойчивому развитию хозяйствующих субъектов и сельской территории в целом.

Воссоздание производственных качеств земли может осуществляться в одном технологическом процессе с возделыванием сельскохозяйственных культур и/или посредством проведения самостоятельных мероприятий, когда земельный участок временно не используется для производства продукции.

Неблагоприятными условиями для воспроизводственных процессов являются сложность рельефа, приводящая к водной эрозии почв, их разрушению, смыву, деградации, нерациональная структура посевов, несоблюдение требований технологии выращивания культур и соблюдения севооборотов, значительная вариация урожайности и валовых сборов продукции.

\section{Методы и материалы}

Обобщение и интерпретация научной информации, анализ и синтез, методы логического сравнения и систематизации

\section{Результаты}

Земельный фонд в административных границах Пензенской области по состоянию на 1 января 2019 года составляет 4335,2 тыс. га. Структура земель остается 
стабильной на протяжении нескольких лет. Земли лесного фонда занимают 964,5тыс. га $(22,3 \%) ;$ земли особо охраняемых территорий и объектов - 9,2 тыс. га, $70 \%$ из них сосредоточены на территории Кузнецкого района. Сохранение территории лесов и особо охраняемых территорий путем полного или частичного ограничения хозяйственной деятельности является главным элементом экологической системы области.

Площадь земель сельскохозяйственного назначения составляет 3070,6 тыс. га (рис. 1).

4000

2000

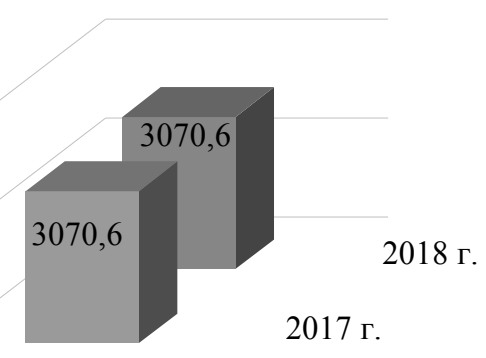

0

Puc. 1. Площадь земель сельскохозяйственного назначения за период 2017-2018 г2., тыс. га

К землям сельскохозяйственного назначения относят всю территорию, предоставленную сельскохозяйственным товаропроизводителям и предназначенную для ведения сельского хозяйства. По хозяйственному использованию эти земли подразделяют на сельскохозяйственные и несельскохозяйственные угодья - площади, занятые лесом, кустарником, болотами, усадьбами и другими угодьями, без которых ведение сельского хозяйства невозможно. Сельскохозяйственные угодья систематически используются для получения сельскохозяйственной продукции; включают пашню, залежь, многолетние насаждения сенокосы и пастбища.

В собственности граждан находится 1153,9 тыс. га или 37,6 \% от общей площади земель сельскохозяйственного назначения, у юридических лиц 863,1 тыс. га $(28,1 \%)$. В государственной и муниципальной собственности находится 1053,6 тыс. га $(34,3 \%)$, из которых 44,3 тыс. га отнесено к собственности Российской Федерации, из них передано в аренду гражданам 7,0 тыс. га, в пользование юридическим лицам - 18,2 тыс. га и в аренду - 16,3 тыс. га. К собственности Пензенской области отнесено 64,5 тыс. га, из них передано в аренду гражданам 5,6 тыс. га, в пользование юридическим лицам 2,3 тыс. га, в аренду юри- дическим лицам - 52,9 тыс. га; 229,1 тыс. га отнесены к муниципальной собственности, из них передано в аренду гражданам 68,3 тыс. га, в пользование юридическим лицам - 1,72 тыс. га и в аренду - 86,9 тыс. га (табл. 1).

Таблица 1

Распределение земель с.-х. назначения Пензенской области по различным формам собственности, тыс. га

\begin{tabular}{|l|c|c|c|}
\hline \multicolumn{1}{|c|}{ Собственность } & 2013 г. & 2018 г. & $\begin{array}{c}2018 \text { г. } \\
\text { в \% к } \\
\text { уровню } \\
2013 \text { г. }\end{array}$ \\
\hline Граждан & 1415,8 & 1153,9 & 81,5 \\
\hline Юридических лиц & 591,8 & 863,1 & 145,9 \\
\hline $\begin{array}{l}\text { Государственная } \\
\text { и муниципальная }\end{array}$ & 1065,3 & 1053,6 & 98,9 \\
\hline Федерации & 39,2 & 44,3 & 113,1 \\
\hline $\begin{array}{l}\text { Субъекта } \\
\text { Федерации }\end{array}$ & 58,7 & 64,5 & 109,9 \\
\hline
\end{tabular}

Динамика распределения земель сельскохозяйственного назначения за период с 2013 по 2018 годы свидетельствует об уменьшении площадей, находящихся в собственности граждан, на 18,5 \%. По состоянию на 01.01.2019 г. в области насчитывалось 242007 личных подсобных хозяйства, осуществляющих производство продукции.

Удельный вес земель, находящихся в собственности юридических лиц, напротив, увеличился на 45,9 \%. Около $94 \%$ земель приходится на долю юридических лиц, зарегистрированных в таких организационноправовых формах как хозяйственные товарищества и производственные кооперативы. Распределение площади земель между предприятиями и организациями различных форм собственности представлено на рисунке 2.

Шестьдесят семь сельскохозяйственных организаций прекратили свое существование (не значатся в едином государственном реестре юридических лиц), но процедура прекращения права на землю не завершена. Площадь ликвидированных организаций составляет 46,5 тыс. га $(2,45 \%$ от общей площади земель юридических лиц).

Наиболее интенсивно используемая часть сельскохозяйственных угодий - пашня. На долю пашни приходится более $70 \%$ сельскохозяйственных угодий области (табл. 2).

Из таблицы видно, что в 2018 году произошли незначительные изменения в структуре земель сельскохозяйственного назначения, площади сельскохозяйствен- 


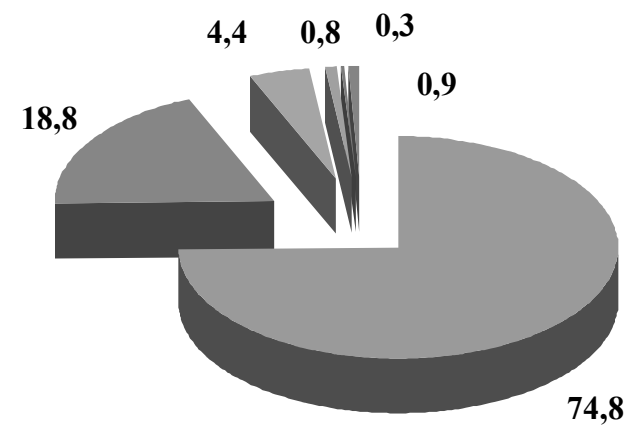
- Хозяйственные товарищества и общества
- Производственные кооперативы
- Государственные и муниципальные унитарные сельскохозяйственные предприятия
Научно-исследовательские и учебные учреждения и заведения
П Подсобные хозяйства
Прочие предприятия и организации

\section{Pис. 2. Распределение общей площади земель между предприятиями и организациями с различными формами собственности, \%}

ных угодий уменьшились на 0,8 \%, площади лесов и кустарников на $0,1 \%$ за счет их передачи под хозяйственные застройки.

Часть земель подвержена негативным процессам: эрозионно-опасные земли составили 16,12 тыс. га, из них подвержено водной эрозии - 10,15 тыс. га; подтоплению - 0,92 тыс. га; переувлажнению - 0,51 тыс. га; каменистости - 2,13 тыс. га; заболачиванию - 0,45 тыс. га; засолению 0,02 тыс. га; участки радиационного загрязнения - 1,89 тыс. га.

Система воспроизводства земельных ресурсов предполагает объединение и взаимосвязь следующих элементов: правовое обеспечение и регулирование земельных отношений, кадастровый учет, организацию и контроль целевого рационального использования земель, функционирование подсистемы экономических ре- гуляторов (рис. 3).

Функционирование системы базируется на Конституции РФ; Гражданском и Земельном кодексах РФ; Федеральных законах: от 18.06.2001 № 78-Ф3 «О землеустройстве», от 24.07.2002 № 101-Ф3 «Об обороте земель сельскохозяйственного назначения», от 24.07.2008 № 221-Ф3 «О кадастровой деятельности»; от 21.12.2004 № 172-Ф3 «О переводе земель или земельных участков из одной категории в другую»; Постановлениях Правительства Российской Федерации: от 29.12.2008 № 1061 «Об утверждении положения о контроле за проведением землеустройства»; от 11.07.2002 № 514 «Об утверждении Положения о согласовании и утверждении землеустроительной документации, создании и ведении государственного фронда данных, полученных в результате проведения землеустройства».

Таблица 2

Распределение земель сельскохозяйственного назначения Пензенской области по угодьям, тыс. га

\begin{tabular}{|l|c|c|c|}
\hline \multicolumn{1}{|c|}{ Показатель } & 2017 г. & 2018 г. & $\begin{array}{c}\text { Отклонение } \\
2018 \text { г. от 2017 г. }\end{array}$ \\
\hline Всего сельскохозяйственных угодий & 2881,3 & 2880,5 & $-0,8$ \\
\hline из них пашни & 2195,5 & 2195,0 & $-0,5$ \\
\hline Леса и кустарники & 77,8 & 77,7 & $-0,1$ \\
\hline Болота & 7,7 & 7,7 & \\
\hline Под водой & 22,3 & 22,4 & $+0,1$ \\
\hline Под дорогами, прогонами, улицами и площадями & 39,0 & 38,9 & $-0,1$ \\
\hline Застроенные территории & 15,4 & 16,4 & $+1,0$ \\
\hline Нарушенные земли & 0,4 & 0,4 & - \\
\hline Прочие земли & 22,9 & 22,8 & $-0,1$ \\
\hline Итого & 3070,6 & 3070,6 & - \\
\hline
\end{tabular}


Основным законодательным актом Пензенской области выступает Закон от 04.03.2015 № 2693-3ПО «О регулировании земельных отношений на территории Пензенской области». Инструментом регулирования выступает мониторинг земель. В Пензенской области для проведения мониторинга земель создана сеть из 14 стационарных участков в 13 административных районах на территории сельскохозяйственных предприятий. В течение 2018 года был проведен кадастровый учет 27083 земельных участков, обследование 195,0 тыс. га на предмет содержания валовых форм тяжелых металлов, радионуклидов, остатков пестицидов. Результаты исследования показали, что эколого-токсилогическое состояние сельскохозяйственных угодий Пензенской области не представляет опасности для ведения сельского хозяйства и позволяет получать экологически чистую продукцию (табл. 3).

В ходе мониторинга в 2018 году было выявлено 1309 нарушений земельного законодательства, наложено штрафов на сумму 6150,3 тысяч рублей. Основным ви-

\section{Система организации воспроизводства земельных ресурсов}

Организация оборота земель

Организация эффективного использования земель правовой аспект, кадастровый учет земель, целевое использование земель, обеспечение прозрачности сделок с землей, государственное регулирование рынка, контроль за сделками с землей, рациональное землепользование

рациональная организация территории, научнообоснованное использование севооборотов, удобрений и средств защиты растений, новых технологий земледелия, вовлечение в оборот всех продуктивных земель, развитие экологоландшафтного земледелия, повышение экологизации почв

\section{Организация управления} земельными ресурсами

Функционирование подсистемы экономических регуляторов согласование интересов государства и собственников земли, согласованность использования земель и управления территориями, иерархия управления земельными ресурсами, обеспечение непрерывности процесса производства, повышение эффективности использования земли и др.

Налог на землю, плата за аренду земли, рыночная, кадастровая, залоговая цена земли, компенсационные платежи за изъятие или консервацию земли, размер платы за сервитуты, налоговое обложение при гражданском земельном обороте

Puc. 3. Элементы системы воспроизводства земельных ресурсов 
Показатели эффрективности земельного контроля

\begin{tabular}{|l|c|c|c|c|c|}
\hline \multicolumn{1}{|c|}{ Показатель } & 2016 г. & 2017 г. & 2018 г. & $\begin{array}{c}\text { Цепной } \\
\text { темп } \\
\text { роста, \% }\end{array}$ & $\begin{array}{c}\text { Базисный } \\
\text { темп } \\
\text { роста, \% }\end{array}$ \\
\hline Выявлено нарушений & 1580 & 1409 & 1309 & 92,9 & 82,9 \\
\hline $\begin{array}{l}\text { Привлечено нарушителей к админист- } \\
\text { ративной ответственности }\end{array}$ & 1370 & 894 & 702 & 51,3 & 78,6 \\
\hline $\begin{array}{l}\text { Наложено штрафов на общую сумму, } \\
\text { тыс. руб. }\end{array}$ & 10243,6 & 6967,8 & 6150,3 & 60,1 & 88,3 \\
\hline
\end{tabular}

дом нарушения земельного законодательства явилось самовольное занятие земельного участка или его части, использование земельного участка лицом, не имеющим предусмотренных законодательством прав.

Воссоздание продуктивных свойств земли предполагает проведение хозяйствующими субъектами разносторонних мероприятий: закрепление овражно-балочной сети, регулирование поверхностного стока, создание оптимального профиля почвы, восстановление естественных биоценозов, нормирование выпаса скота, увеличение площадей, занятых сидеральными культурами и др.

Низкая платежеспособность и финансовая неустойчивость хозяйствующих субъектов приводит к низкой эффективности воспроизводственных процессов и, наоборот, эффективное ведение расширенного воспроизводства обусловливает лучшие возможности устойчивого развития хозяйствующего субъекта.

Об эффективности использования и воспроизводства сельскохозяйственных угодий позволяют судить показатели урожайности сельскохозяйственных культур, валового сбора продукции в натуральном и стоимостном выражениях, динамика балла бонитета почвы (рис. 4).

Для сравнительной характеристики процессов воспроизводства могут быть использованы относительные комбинированные переменные, например, объем производства продукции в расчете на один балл бонитета почвы или на рубль кадастровой стоимости земли (табл. 4).

В таблице представлена группировка 27 районов Пензенской области по качественному составу почв. В состав группы с лучшими почвами и землями вошло семь районов: Башмаковкий, Бековский, Иссинский, Каменский, Колышлейский, Спасский

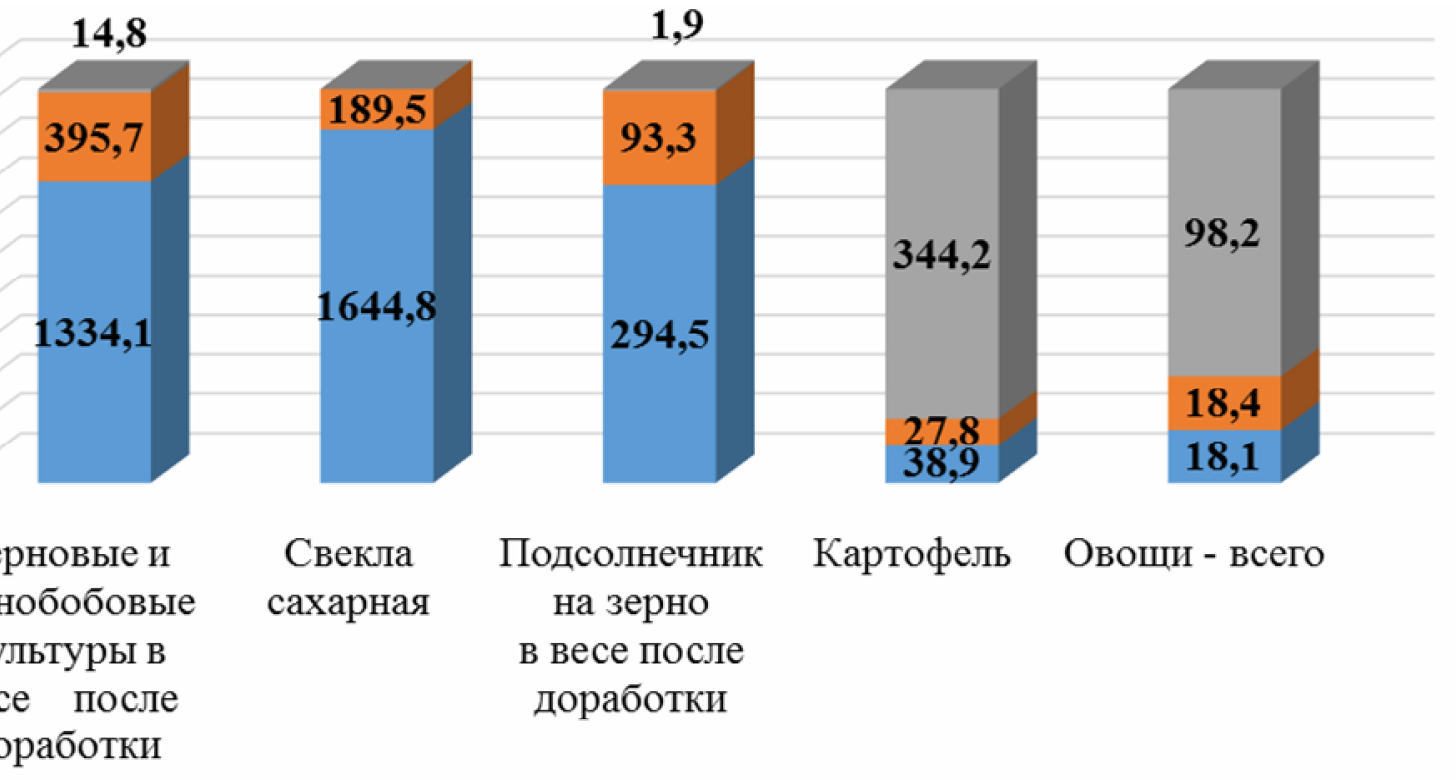

\section{॥ Хозяйства населения}

- Крестьянские (фермерские) хозяйства и индивидуальные предприниматели

- Сельскохозяйственные организации

Puc. 4. Валовый сбор сельскохозяйственных культур

в разрезе отдельных фоорм хозяйствования за 2018 г., тыс. и 
Показатели эфффективности использования сельскохозяйственных угодий в 2018 г.

\begin{tabular}{|c|c|c|c|c|c|c|c|}
\hline \multirow{2}{*}{$\begin{array}{c}\text { Общая } \\
\text { характеристика } \\
\text { качества } \\
\text { почв и земель }\end{array}$} & \multirow{2}{*}{$\begin{array}{c}\text { Балл } \\
\text { бонитета } \\
\text { почв и } \\
\text { оценки } \\
\text { земель }\end{array}$} & \multirow{2}{*}{$\begin{array}{c}\text { Коли- } \\
\text { чество } \\
\text { рай- } \\
\text { онов }\end{array}$} & \multirow{2}{*}{$\begin{array}{c}\text { Средняя } \\
\text { кадастро- } \\
\text { вая стои- } \\
\text { мость, } \\
\text { руб. за } \\
1 \text { га }\end{array}$} & \multirow{2}{*}{\begin{tabular}{|c|} 
Сред- \\
ний \\
балл \\
боните- \\
та с.-х. \\
угодий
\end{tabular}} & \multirow{2}{*}{$\begin{array}{c}\text { Средний объем } \\
\text { производства с.- } \\
\text { Х. продукции (в } \\
\text { фактически дей- } \\
\text { ствующих це-- } \\
\text { нах), тыс. руб. }\end{array}$} & \multicolumn{2}{|c|}{$\begin{array}{c}\text { Объем производст- } \\
\text { ва в расчете }\end{array}$} \\
\hline & & & & & & $\begin{array}{c}\text { на } 1 \\
\text { балл } \\
\text { бони- } \\
\text { тета }\end{array}$ & $\begin{array}{l}\text { на } 1 \text { руб. } \\
\text { кадастро- } \\
\text { вой стои- } \\
\text { мости }\end{array}$ \\
\hline $\begin{array}{l}\text { Лучшие почвы и зем- } \\
\text { ли }\end{array}$ & $71-100$ & 7 & 62029 & 74 & 2528964 & 34175 & 41 \\
\hline $\begin{array}{l}\text { Средние почвы и } \\
\text { земли }\end{array}$ & $31-70$ & 20 & 47050 & 60 & 2763606 & 46060 & 59 \\
\hline $\begin{array}{l}\text { Худшие почвы и зем- } \\
\text { ли }\end{array}$ & $1-30$ & - & - & - & - & - & - \\
\hline
\end{tabular}

и Тамалинский. Средняя кадастровая стоимость земли в данных районах на $31,8 \%$ выше, чем в районах со средними по качеству почвами, куда вошли остальные 20 районов: Белинский, Бессоновский, Вадинский, Городищенский, Земетчинский, Камешкирский, Кузнецкий, Лопатинский, Лунинский, Малосердобинский, Мокшанский, Наровчатский, Неверкинский, Нижнеломовский, Никольский, Пачелмский, Пензенский, Сердобский, Сосновоборский и Шемышейский.

Следует отметить, что в районах с наиболее плодородными почвами показатель среднего объема производства сельскохозяйственной продукции ниже на 8,5\%, по сравнению с районами, где качество почвы на порядок ниже. А следовательно, и коэфффициент качества использования зе- мель ниже на 18 единиц. Данный факт свидетельствует о том, что сельхозпроизводители, имеющие менее выгодные природные объекты с точки зрения их качественной составляющей, прилагают большие усилия по интенсификации использования земельных участков.

\section{Заключение}

Проведенные исследования показали, что систему воспроизводства земельных ресурсов Пензенской области необходимо совершенствовать во всех направлениях: развивать земельное законодательство, своевременно и оперативно решать вопросы, связанные с рациональным использованием земель. Вести федеральный надзор за рациональным использованием и воспроизводством земель сельскохозяйственного назначения.

\section{Лumepamypa}

1. Конституция Российской Федерации (принята всенародным голосованием 12.12.1993) (с учетом поправок, внесенных Законами РФ о поправках к Конституции РФ от 30.12.2008 № 6-ФКЗ, от 30.12.2008 № 7-ФКЗ, от 05.02.2014 № 2-ФКЗ, от 21.07.2014 № 11-ФКЗ) // Справочно-правовая система «КонсультантПлюс».

2. Гражданский кодекс Российской Федерации. (Часть первая) от 30.11.1994 № 51-Ф3 (ред. от 18.07.2019) (с изм. и доп., вступ. в силу с 01.10.2019) // Справочно-правовая система «КонсультантПлюс».

3. Земельный кодекс Российской Федерации от 25.10.2001 № 136-Ф3 (ред. от 02.08.2019) // Справочно-правовая система «КонсультантПлюс».

4. О землеустройстве: Федеральный закон № 78-Ф3: от 18.06.2001 (ред. от 02.08.2019) // Справочно-правовая система «КонсультантПлюс».

5. Об обороте земель сельскохозяйственного назначения: Федеральный закон № 101-Ф3: от 24.07.2002 (ред. от 06.06.2019) // Справочно-правовая система «КонсультантПлюс».

6. О кадастровой деятельности: Федеральный закон № 221-Ф3: от 24.07.2007 (ред. от 02.08.2019) (с изм. и доп., вступ. в силу с 16.09.2019) // Справочно-правовая система «КонсультантПлюс».

7. О переводе земель или земельных участков из одной категории в другую: Федеральный закон № 172-Ф3: от 21.12.2004 (ред. от 01.05.2019) (с изм. и доп., вступ. в силу с 01.07.2019) // Справочно-правовая система «КонсультантПлюс».

8. Постановление Правительства РФ от 29 декабря 2008 г. № 1061 Об утверждении Положения о контроле за проведением землеустройства // Справочно-правовая система «КонсультантПлюс».

9. О регулировании земельных отношений на территории Пензенской области: Закон Пензенской области № 2693-3ПО от 04.03.2015: принят 3С Пензенской обл. 20.02.2015 // Справочноправовая система «КонсультантПлюс».

10. База данных показателей муниципальных образований. URL: https://pnz. gks. ru/ (дата обращения 10.10.2019). - Текст: электронный. 
11. Пензенская область 2018 в цифрах. URL: https://pnz. gks. ru/ (дата обращения 10.10.2019). Текст: электронный.

12. Показатели для оценки эффективности деятельности органов местного самоуправления городских округов и муниципальных районов, находящимся в компетенции Росстата. URL: https://pnz. gks. ru/ (дата обращения 10.10.2019). - Текст: электронный.

13. Производство продукции сельского хозяйства по категориям хозяйств. URL: https://pnz. gks. ru/ (дата обращения 10.10.2019). - Текст: электронный.

14. Сельское хозяйство, охота и лесное хозяйство. URL: https://pnz. gks. ru/ (дата обращения 10.10.2019). - Текст: электронный.

15. Strategic models of optimization of support of farmers / D. Samygin, N. Baryshnikov, L. Vinnichek, I. Glasunov // Ponte. - 2017. - V. 73. - № 4. - P. 146-157.

16. Samygin, D. Models of investment appeal of agribusiness in Russian regions / D. Samygin, N. Baryshnikov, N. Shlapakova // Ponte. - 2017. - V. 73. - № 2. - P. 344-351.

17. Gushchina, V. A. The substantiation of the seeding rate of spring rape in the conditions of unstable moistening of forest-steppe of the middle volga region / V. A. Gushchina, A. S. Lykova // Research Journal of Pharmaceutical, Biological and Chemical Sciences. - 2018. - V. 9. - № 1. - P. 149154.

UDC 330

DOI: $10.36461 / N P .2019 .52 .3 .008$

\section{TO THE PROBLEM OF REPRODUCTION OF LAND RESOURCES OF PENZA REGION}

E. N. Nikiforova, Candidate of Economic Sciences, Professor; Yu. Yu. Rassypnova, Assistant-professor; N. M. Guryanova, Candidate of Economic Sciences, Assistant-professor

Federal State Budgetary Educational Institution of Higher Education «Penza State Agrarian University», Russia, t. (841-2) 628-376, e-mail: rzyankina-natalya@yandex.ru

The article presents material on the problem of the reproduction of land resources in Penza region, the main aspects of which are essential today and which are included as priority areas for the implementation of a number of state programs and other legislative acts. The problem of the distribution of agricultural land by various forms of ownership and by land is discussed. The system of reproduction of land resources is based on the integration of legal, organizational, accounting, functional aspects and control over their intended use. The effectiveness of this system is expressed in effective indicators: crop productivity, gross yield, soil bonitet. Relative variables can also be used as comparative characteristics of the reproduction process: the volume of production per one point of soil bonitet or per ruble of the cadastral value of land.

Key words: reproduction, agricultural land, land distribution, agricultural production.

\section{References:}

1. The Constitution of the Russian Federation (adopted by popular vote 12/12/1993) (as amended by the Laws of the Russian Federation on amendments to the Constitution of the Russian Federation dated December 30, 2008 No. 6-ФК3 (federal constitutional law), dated December 30, 2008 No. 7-ФК3, dated February 5, 2014 No. 2 -ФК3, dated July 21, 2014 No. 11-ФК3) // Reference-legal system «Consultant Plus».

2. Civil Code of the Russian Federation. (Part One) dated November 30, 1994 No. 51law) (as amended on July 18, 2019) (as amended and added, entered into force on October 1, 2019) // Reference-legal system "Consultant Plus».

3. The Land Code of the Russian Federation of October 25, 2001 No. 136-FZ (as amended on August 2, 2019) // Reference-legal system «Consultant Plus».

4. On land management: Federal Law No. 78-Ф3: 06/18/2001 (as amended on 02/08/2019) // Reference-legal system «Consultant Plus».

5. On the turnover of agricultural land: Federal Law No. 101-Ф3: dated July 24, 2002 (as amended on June 6, 2019) // Reference-legal system «Consultant Plus».

6. On cadastral activities: Federal Law No. 221-Ф3: dated July 24, 2007 (as amended on August 2, 2019) (as amended and supplemented, entered into force on September 16, 2019) // Reference-legal system «Consultant Plus».

7. On the transfer of land or land from one category to another: Federal Law No. 172-Ф3: dated 21.12.2004 (as amended on 05/01/2019) (as amended and supplemented, entered into force on 01/01/2019) // Reference-legal system «Consultant Plus». 
8. Decree of the Government of the Russian Federation of December 29, 2008 No. 1061 On approval of the Regulation on the monitoring of land management // Reference-legal system "Consultant Plus».

9. On the regulation of land relations in Penza region: Law of Penza region No. 2693-3חO dated 04.03.2015: adopted by the legislative meeting of Penza region. 02/20/2015 // Reference-legal system «Consultant Plus».

10. Database of indicators of municipalities. URL: https://pnz. gks. ru/ (accessed 10.10.2019). - Text: electronic.

11. Penza region 2018 in numbers. URL: https://pnz. gks. ru/ (accessed 10.10.2019). - Text: electronic.

12. Indicators for evaluating the performance of local authorities of urban districts and municipal areas within the competence of Rosstat. URL: https://pnz. gks. ru/ (accessed 10.10.2019). - Text: electronic.

13. Production of agricultural products by categories of farms. URL: https://pnz. gks. ru/ (accessed 10.10.2019). - Text: electronic.

14. Agriculture, hunting and forestry. URL: https://pnz. gks. ru/ (accessed 10.10.2019). - Text: electronic.

15. Strategic models of optimization of support of farmers / D. Samygin, N. Baryshnikov, L. Vinnichek, I. Glasunov // Ponte. - 2017. - V. 73. - № 4. - P. 146-157.

16. Samygin, D. Models of investment appeal of agribusiness in Russian regions / D. Samygin, N. Baryshnikov, N. Shlapakova // Ponte. - 2017. - V. 73. - № 2. - P. 344-351.

17. Gushchina, V. A. The substantiation of the seeding rate of spring rape in the conditions of unstable moistening of forest-steppe of the middle volga region / V. A. Gushchina, A. S. Lykova // Research Journal of Pharmaceutical, Biological and Chemical Sciences. - 2018. - V. 9. - № 1. - P. 149-154. 